\title{
Prevalence of depression and anxiety among chronic obstructive pulmonary disorder patients and its impact on the severity of the disease
}

\author{
Kamini $\mathrm{B}^{1}$, Gopinath $\mathrm{TT}^{2}$, Balamurugan $\mathrm{S}^{3}$, Arun Jayakumar $\mathrm{U}^{4}$, Harish Narayanan ${ }^{5}$ \\ ${ }^{1}$ Associate Professor, ${ }^{4}$ Assistant Professor, Department of Community Medicine, ${ }^{3}$ Professor and Head, Department \\ of Pulmonology, Sri Muthukumaran Medical College and Research Institute, Chennai, ${ }^{2}$ Associate Professor, \\ ${ }^{5}$ Assistant Professor, Department of Community Medicine, Meenakshi Medical College and Research Institute, \\ Meenakshi Academy of Higher Education and Research, Kanchipuram, Tamil Nadu, India
}

Background: There is high prevalence of anxiety and depression in chronic obstructive pulmonary disease (COPD) patients, leading to habits such as smoking. Aims and Objectives: This study aims to relate quantitatively, the contribution of anxiety and depression on prognosis, smoking, and stage of the disease. Materials and Methods: This cross-sectional study was conducted over a period of 3 months on 50 male COPD patients, aged 40-70 years. Patients were recruited to participate in the study after obtaining informed consent and were administered a questionnaire. They were subjected for detailed clinical examination, chest- $X$ ray. CAT, BODE, GOLD stage, MADRS, and HAM-A were calculated and submitted for statistical analysis. Results: Depression had more influence on smoking rather than anxiety. There was no contributing influence by age. Conclusion: Clinicians should be encouraged to concentrate more on addressing depression rather than anxiety.

Key words: Anxiety; Chronic obstructive pulmonary disease; Depression
Access this article online

\section{Website:}

http://nepjol.info/index.php/AJMS

DOI: 10.3126/ajms.v13i1.40563

E-ISSN: 2091-0576

P-ISSN: 2467-9100

Copyright (c) 2022 Asian Journal of Medical Sciences

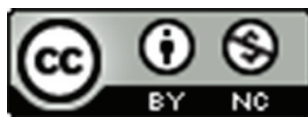

This work is licensed under a Creative Commons Attribution-NonCommercial 4.0 International License.

\section{INTRODUCTION}

Chronic obstructive pulmonary disease (COPD) is the third leading cause of death in the world, of which $80 \%$ of deaths occur in low- and middle-income groups. ${ }^{1}$ It is observed as a progressive life-threatening lung disease which causes breathlessness (on exertion initially) and later predisposes to exacerbation and serious illness. ${ }^{2}$ The cases are on the rise due to pollution and lifestyle changes. Since this disease is impacting a large population, many health bodies are around the world, which are making efforts to prevent and treat this health issue.

However, considerable amount of anxiety and depression is associated with this disease due to the symptoms and presentation of the disease. ${ }^{3}$ This decreases the quality of life as it affects function of daily life by affecting physical roles, emotional, and social roles of the affected person. ${ }^{4}$ In addition, it increases the frequent medical expenses in addition to the expenses caused by the actual disease. Further, anxiety may be related to the disease characteristics, as it causes change in breathing and dyspnea. ${ }^{5}$ The hyper-ventilation caused as a result of physiological arousal mediated increase in breathing frequency results in shortness of breath, bronchoconstriction, and lung hyperinflation, having further deleterious effects on the patient. ${ }^{6}$ Therefore, there is a definite need to address the anxiety and depression in a COPD patient. 
Various studies have found out that the depression and anxiety scores were significantly associated with the severity of COPD. ${ }^{7-9}$ Smoking, depression, anxiety, and COPD all form an interwoven web. Smoking is a proven risk factor for COPD. A person in depression seeks smoking as a relief factor. Hence, this leads to a vicious cycle. Meta-analysis of controlled studies has revealed the mean prevalence of depression and 95\% CI to be $27.1 \%$ (25.9-28.3). ${ }^{10}$ In general, the symptoms of anxiety and depression in COPD patients are overshadowed by other somatic conditions. Hence, the diagnosis and treatment of these common psychiatric comorbidities in them are delayed. Certain studies have shown that lesser than one-third of COPD patients with psychiatric comorbidities were provided with appropriate treatment. ${ }^{11}$

However, there is a lacuna in the literature regarding statistical association anxiety, depression, severity of disease, and so-called consequent smoking. This study is conducted to evaluate if such a relation is present and study it quantitatively.

\section{Aims and objectives}

1. To estimate the Prevalence of Depression and Anxiety among Chronic Obstructive Pulmonary Disease(COPD) Patients.

2. To assess the impact of the above on the Severity of the disease.

\section{MATERIALS AND METHODS}

This cross-sectional study was conducted at the Outpatient department of Chest Medicine at Sri Muthukumaran Medical College and Hospital, Chennai, after the approval from the Institute's Ethical Committee. Fifty COPD patients were chosen for the study over a period of 3 months.

\section{Inclusion criteria}

The study included only male COPD patients in the age group of 40-70 years who are smokers (current or in the past with at least 10 pack-years).

\section{Exclusion criteria}

The study excluded women, non-smokers, men over 70 years of age, and also individuals unwilling to undergo pulmonary function tests.

The study subjects were requested to participate in the study and a written informed consent in Tamil language was obtained. They were administered a detailed questionnaire pertaining to the baseline data, smoking history, and other details about duration and severity of COPD symptoms. After medical history, the individual's BMI was recorded. They were subjected for detailed clinical examination and chest- $\mathrm{X}$ ray. CT chest was taken in required cases only. CAT (COPD assessment test) which is an 8-item containing unidimensional measure of impairment in health status of COPD patients. Unpacked 6 min walk test was performed to assess the exercise tolerance and physical activity. Modified Medical Research Council scale was applied for obtaining dyspnea scores. History of moderate/severe exacerbations of symptoms was obtained. BODE, a composite score, that serves as a good predictor for severity of disease and subsequent survival rate was calculated. Spirometric assessment was done after administration of short-acting inhaled bronchodilator. COPD diagnosis was done as per GOLD guidelines. ${ }^{12}$ Anxiety was measured using Hamilton anxiety scale (HAM-A), while depression was measured using Montgomery-Asberg depression scale (MADRS). ${ }^{13,14}$

\section{RESULTS}

The samples had a mean age of about 55 years, with smoking index of 18.39, BODE of 2.78, HAM-A of 2.92, and MADRS of 10.26, as shown in Table 1.

The most common GOLD staging was 2 . In our study, the prevalence of mild anxiety was $56 \%$ and moderate anxiety was $12 \%$. There was no practical correlation between age and anxiety, depression, and prognosis as demonstrated in Table 2.

Multiple regression showed that anxiety and depression were less significantly contributing to smoking but it is the stage of disease that had contributed more, as shown in Table 3.

Table 4 shows that anxiety is inversely related to prognosis scale and depression is positively related.

Table 5 shows that stage of the disease is significantly

\begin{tabular}{|c|c|c|c|c|c|}
\hline & Age & $\begin{array}{c}\text { Smoking } \\
\text { index }\end{array}$ & BODE & HAM-A & MADRS \\
\hline Mean & 55.74 & 18.39 & 2.78 & 2.92 & 10.26 \\
\hline SD & 7.6340 & 5.9925 & 1.5022 & 3.2940 & 6.4072 \\
\hline Min & 41 & 11 & 0 & 0 & 3 \\
\hline Max & 72 & 41 & 7 & 19 & 31 \\
\hline
\end{tabular}




\section{Table 2: Correlation between individual relevant factors}

\begin{tabular}{llc} 
Relation & Level of correlation & Correlation coefficient (r) \\
\hline Age with anxiety & Nil & 0.0259 \\
Age with depression & $\mathrm{Nil}$ & 0.0397 \\
Age with BODE (prognosis) & $\mathrm{Nil}$ & 0.2190 \\
Smoking with depression & Moderate & 0.0856 \\
Smoking with anxiety & Low & 0.5096 \\
Bode with HAMA & Nil & 0.00189 \\
Bode with MADRS & Low & 0.0994 \\
GOLD stage with HAMA & Low & $3.08 \mathrm{E}-31^{*}$ \\
GOLD with MADRS & Moderate & 0.3771 \\
\hline HAM-A: Hamilton anxiety scale, MADRS: Montgomery-Asberg depression scale. *Significant & 0.1786 \\
\end{tabular}

Table 3: Multivariate regression to associate HAM-A, MADRS, and GOLD stage with smoking (Smoking as a function of various factors)

\begin{tabular}{|c|c|c|c|c|c|}
\hline \multirow{2}{*}{$\begin{array}{l}\text { Model: } \\
\text { Predictor }\end{array}$} & \multicolumn{5}{|c|}{ SMOKING=0.6091-0.0913.HAMA+0.075.MADRS+0.6619.GOLD stage } \\
\hline & Coefficient & Estimate & Standard error & t-statistic & P-value \\
\hline Constant & $\beta 0$ & 0.6091 & 0.5091 & 1.1965 & 0.2376 \\
\hline HAMA & $\beta 1$ & -0.0913 & 0.0786 & -1.1617 & 0.2513 \\
\hline MADRS & $\beta 2$ & 0.075 & 0.0447 & 1.6764 & 0.1004 \\
\hline GOLD stage & $\beta 3$ & 0.6619 & 0.2144 & 3.087 & $0.0034^{*}$ \\
\hline \multicolumn{6}{|c|}{ Summary of overall fit } \\
\hline R-squared & \multicolumn{5}{|c|}{$r^{2}=0.3325$} \\
\hline Adjusted R-s & \multicolumn{5}{|c|}{$r^{2}$ adj $=0.289$} \\
\hline Residual star & \multicolumn{5}{|c|}{1.2667 on 46 degrees of freedom. } \\
\hline Overall F-sta & \multicolumn{5}{|c|}{7.6375 on 3 and 46 degrees of freedom. } \\
\hline Overall $P$ valt & \multicolumn{5}{|c|}{$0.0003^{*}$} \\
\hline
\end{tabular}

HAM-A: Hamilton anxiety scale, *MADRS: Montgomery-Asberg depression scale

\begin{tabular}{|c|c|c|c|c|c|}
\hline \multirow{2}{*}{$\begin{array}{l}\text { Model: } \\
\text { Predictor }\end{array}$} & \multicolumn{5}{|c|}{ BODE=1.763-0.145.HAMA+0.1404.MADRS } \\
\hline & Coefficient & Estimate & Standard error & t-statistic & P-value \\
\hline Constant & $\beta 0$ & 1.763 & 0.3756 & 4.6932 & 0 \\
\hline HAMA & $\beta 1$ & -0.145 & 0.0833 & -1.7413 & 0.0882 \\
\hline MADRS & $\beta 2$ & 0.1404 & 0.0428 & 3.2787 & $0.002^{*}$ \\
\hline \multicolumn{6}{|c|}{ Summary of overall fit } \\
\hline \multicolumn{3}{|l|}{ R-squared } & \multicolumn{3}{|c|}{$r^{2}=0.1942$} \\
\hline \multicolumn{3}{|c|}{ Residual standard error } & \multicolumn{3}{|c|}{1.3769 on 47 degrees of freedom. } \\
\hline \multicolumn{3}{|c|}{ Overall F-statistic } & \multicolumn{3}{|c|}{5.6634 on 2 and 47 degrees of freedom. } \\
\hline \multicolumn{2}{|c|}{ Overall $P$ value } & & \multicolumn{3}{|c|}{$0.0063^{*}$} \\
\hline
\end{tabular}

HAM-A: Hamilton anxiety scale, *MADRS: Montgomery-Asberg depression scale

Table 5: Multivariate regression to associate HAM-A and MADRS with GOLD stage

\begin{tabular}{|c|c|c|c|c|c|}
\hline \multirow{2}{*}{$\begin{array}{l}\text { Model: } \\
\text { Predictor }\end{array}$} & \multicolumn{5}{|c|}{ GOLD stage $=1.7432-0.0812 \cdot \mathrm{HAMA}+0.0988 \cdot \mathrm{MADRS}$} \\
\hline & Coefficient & Estimate & Standard error & t-statistic & p-value \\
\hline Constant & $\beta_{0}$ & 1.7432 & 0.2351 & 7.4148 & 0 \\
\hline MADRS & $\beta_{2}$ & 0.0988 & 0.0268 & 3.6871 & $0.0006^{*}$ \\
\hline \multicolumn{6}{|c|}{ Summary of overall fit } \\
\hline \multicolumn{3}{|c|}{ R-squared } & \multicolumn{3}{|c|}{$r^{2}=0.2491$} \\
\hline \multicolumn{2}{|c|}{ Residual standard error } & & \multicolumn{3}{|c|}{0.8617 on 47 degrees of freedom. } \\
\hline \multicolumn{2}{|c|}{ Overall F-statistic } & & \multicolumn{3}{|c|}{7.7961 on 2 and 47 degrees of freedom. } \\
\hline \multicolumn{2}{|c|}{ Overall $P$ value } & & \multicolumn{3}{|c|}{$0.0012^{*}$} \\
\hline
\end{tabular}

HAM-A: Hamilton anxiety scale, *MADRS: Montgomery-Asberg depression scale 
influenced by depression but not anxiety. Therefore, by virtue of the tables presented, one can infer that depression is more related to smoking induction, prognosis, and disease stage compared with anxiety.

\section{DISCUSSION}

In our study, the prevalence of mild anxiety was 56\% and moderate anxiety was $12 \%$. This is comparable to a study conducted by Willgoss and Yohannes (2013) with prevalence of clinical anxiety in COPD outpatients ranging from $13 \%$ to $46 \% .{ }^{15}$ In a study by Elassal et al., the prevalence of depression was reported to be $42.5 \%$ and anxiety prevalence was $22.5 \% .{ }^{8}$ Various studies have shown the prevalence of depression in range of $16.5 \%-27.4 \%$. The prevalence rate of mild depression in our present study is $96 \%$ and moderate depression is $2 \%$. Putcha et al., have stated that depression is associated with outcomes of COPD patients, in terms of exacerbations risk, re-hospitalization risk, and inability to perform activities of daily living. ${ }^{16}$ In this regard, there is an uneven distribution of anxiety and depression scales in the sample, characteristically describing the heterogeneity in stages of disease. Therefore, the sample is good to assess various correlations.

Anxiety and depression are well known to be associated with COPD.${ }^{17}$ As a result, such patients seek other ways to dissipate their psychological stress and resort to smoking. In this case, smoking is detrimental to COPD and the vicious cycle continues to worsen the prognosis. As one can observe, removing one factor can prevent the cycle, of which current paper focuses on addressing the anxiety levels. It is shown that the treatment of depressed or anxious COPD patients is similar to treating non-COPD patients of similar psychiatric conditions. ${ }^{18,19}$ However, the association of these psychiatric disorders with severity of disease and with smoking is being the concern that is addressed here. This aspect of the vicious cycle is the key point in addressing the entire issue.

There was no practical correlation between age and anxiety, depression, and prognosis. Therefore, age needs not be a factor in this vicious cycle being addressed. Some papers have highlighted that COPD is more prevalent with age. ${ }^{20}$ Furthermore, some reports suggest that younger people with COPD are more depressed. ${ }^{21}$ There was a moderate and statistically significant correlation between smoking and depression $(\mathrm{R}=0.5)$. This means that smoking habit may be a result of depression. However, correlation of anxiety with smoking is low $(\mathrm{R}=0.2)$, implying the lower contribution of anxiety compared to depression. While there was no practical correlation between anxiety and prognosis, depression had low correlation with prognosis and moderate correlation with stage of the disease. Furthermore, there was a very low correlation between anxiety and stage of disease $(\mathrm{R}=0.17)$. This seems to be interesting as one might expect increase in anxiety with stage of disease. ${ }^{22}$ However, the selected age group and smaller sample size may have contributed to this factor.

To associate psychiatric states with smoking, multiple regression calculations were made (Table 3). It was seen that anxiety and depression were not significantly contributing to smoking but stage of disease does. Table 4 shows that prognosis is affected by depression. According to the regression equation, anxiety in inversely related to prognosis scale and depression is positively related. The depression is significantly associated while anxiety is not. Similarly, in Table 5, stage of the disease is significantly influenced by depression but not anxiety. Therefore, by virtue of the tables presented, one can infer that depression is more related to smoking induction, prognosis, and disease stage compared with anxiety.

The relation between smoking and mortality in COPD has been discussed by Lou et al. ${ }^{23}$ According to them, about $60 \%$ of the mortality in COPD patients were associated or linked with an interaction of smoking and depression. Furthermore, about $50 \%$ of the deaths of COPD subjects were linked with smoking and anxiety symptoms. Lou et al., in another paper, have highlighted that both depression and anxiety were associated with higher mortality in COPD patients. ${ }^{24}$ Goodwin et al., have hypothesized that the association of COPD and mood disorders may be due to exposure to a common risk factor, and may not be a causal link between the two. ${ }^{25}$ However, $\mathrm{Ng}$ et al., have proposed that depression was present in COPD independent of other confounding or causal factors. ${ }^{26}$ Nevertheless, there is no information on quantitative association of anxiety and depression with smoking as given by this paper.

This paper has few limitations as recognized by the authors. Primary limitation is the observational nature of the study rather than interventional method, besides small sample size. In future, studies, especially randomized controlled trials, have to be conducted to strongly associate anxiety, depression, prognosis, and smoking.

\section{Limitations of the study}

The study currently involved male patients only as women COPD patients were not forthcoming with their history of smoking due to cultural issues 


\section{CONCLUSION}

The study has thrown valuable light in attempting to associate disease severity, prognosis, depression, and anxiety with smoking. With the present evidence, it can be said that depression is more influential for induction of smoking compared with anxiety. However, age could not be associated with other factors relevantly. Therefore, clinicians should be encouraged to concentrate more on addressing depression. Further studies with large sample sizes in various populations and ethnic groups are needed to clearly quantify the association of anxiety and depression with smoking index.

\section{ACKNOWLEDGMENT}

Nil.

\section{REFERENCES}

1. The Top 10 Causes of Death; 2020. Available from: https://www who.int/news-room/fact-sheets/detail/the-top-10-causes-ofdeath [Last accessed on 2020 Dec 09].

2. World Health Organization. Chronic Obstructive Pulmonary Disease. Geneva: World Health Organization; 2017. Available from: https://www.who.int/news-room/fact-sheets/detail/ chronicobstructive-pulmonary-disease-(copd) [Last accessed on 2021 Jun 21].

3. Di Marco F, Verga M, Reggente M, Casanova FM, Santus $P$, Blasi $\mathrm{F}$, et al. Anxiety and depression in COPD patients: The roles of gender and disease severity. Respir Med. 2006;100(10):1767-1774.

http://doi.org/10.1016/j.rmed.2006.01.026

4. Valenza MC, Valenza-Peña G, Torres-Sánchez I, GonzálezJiménez E, Conde-Valero A and Valenza-Demet G. Effectiveness of controlled breathing techniques on anxiety and depression in hospitalized patients with COPD: A randomized clinical Trial. Respir Care. 2014;59(2):209-215.

http://doi.org/10.4187/respcare.02565

5. Al-Gamal E and Yorke J. Perceived breathlessness and psychological distress among patients with chronic obstructive pulmonary disease and their spouses. Nurs Health Sci. 2014;16(1):103-111.

http://doi.org/10.1111/nhs.12073

6. O'Donnell DE, Banzett RB, Carrieri-Kohlman V, Casaburi R, Davenport PW, Gandevia SC, et al. Pathophysiology of dyspnea in chronic obstructive pulmonary disease: A roundtable. Proc Am Thorac Soc. 2004;4(2):145-168. http://doi.org/10.1513/pats.200611-159CC

7. Janssen DJ, Spruit MA, Leue C, Gijsen C, Hameleers H, Schols JM, et al. Symptoms of anxiety and depression in COPD patients entering pulmonary rehabilitation. Chron Respir Dis. 2010;7(3):147-157. http://doi.org/10.1177/1479972310369285

8. Elassal G, Elsheikh M and Zeid AG. Assessment of depression and anxiety symptoms in chronic obstructive pulmonary disease patients: A case-control study. Egypt J Chest Dis Tuberc. 2014;63(3):575-582.

http://doi.org/10.1016/j.ejcdt.2014.02.013

9. van Manen JG, Bindels PJ, Dekker FW, IJzermans CJ, van der Zee JS and Schadé E. Risk of depression in patients with chronic obstructive pulmonary disease and its determinants. Thorax. 2002;57(5):412-416.

http://doi.org/10.1136/thorax.57.5.412

10. Matte DL, Pizzichini MM, Hoepers AT, Diaz AP, Karloh M, Dias M, et al. Prevalence of depression in COPD: A systematic review and meta-analysis of controlled studies. Respir Med. 2016;117:154-161.

http://doi.org/10.1016/j.rmed.2016.06.006

11. Maurer J, Rebbapragada V, Borson S, Goldstein R, Kunik ME, Yohannes AM, et al. Anxiety and depression in COPD: Current understanding, unanswered questions, and research needs. Chest. 2008;134(Suppl 4):43S-56S.

http://doi.org/10.1378/chest.08-0342

12. Global Initiative of Chronic Obstructive Lung Disease. Global Strategy for Diagnosis, Management, and Prevention of Chronic Obstructive Pulmonary Disease 2019 Report; 2019. Available from: http://www.goldcopd.org. [Last accessed on 2020 May 20].

13. Maier W, Buller R, Philipp M and Heuser I. The Hamilton anxiety scale: Reliability, validity and sensitivity to change in anxiety and depressive disorders. J Affect Disord. 1988;14(1):61-68. http://doi.org/10.1016/0165-0327(88)90072-9

14. Barman D, Mishra S, Mishra J, Mahapatra P and Manjareeka M. Association between depression and acute pain in adults attending a tertiary care hospital in Bhubaneswar. J Clin Diagn Res. 2015;9(7):CC08-CC11. http://doi.org/10.7860/JCDR/2015/12008.6179

15. Willgoss TG and Yohannes AM. Anxiety disorders in patients with COPD: A systematic review. Respir Care. 2013;58(5):858-866. http://doi.org/10.4187/respcare.01862

16. Putcha N, Drummond MB, Wise RA and Hansel NN. Comorbidities and chronic obstructive pulmonary disease: Prevalence, influence on outcomes, and management. Semin Respir Crit Care Med. 2015;36(4):575-591. http://doi.org/10.1055/s-0035-1556063

17. Yohannes AM and Alexopoulos GS. Depression and anxiety in patients with COPD. Eur Respir Rev. 2014;23(133):345-349. http://doi.org/10.1183/09059180.00007813

18. Cho MH, McDonald ML, Zhou X, Mattheisen M, Castaldi PJ, Hersh CP, et al. Risk loci for chronic obstructive pulmonary disease: A genome-wide association study and meta-analysis. Lancet Respir Med. 2014;2(3):214-225. http://doi.org/10.1016/S2213-2600(14)70002-5

19. Mercado $\mathrm{N}$, Ito $\mathrm{K}$ and Barnes $\mathrm{PJ}$. Accelerated ageing of the lung in COPD: New concepts. Thorax. 2015;70(5):482-489. http://doi.org/10.1136/thoraxjnl-2014-206084

20. Woldeamanuel GG, Mingude AB and Geta TG. Prevalence of chronic obstructive pulmonary disease (COPD) and its associated factors among adults in Abeshge District, Ethiopia: A cross sectional study. BMC Pulm Med. 2019;19(1):181. http://doi.org/10.1186/s12890-019-0946-z

21. Holm KE, Plaufcan MR, Ford DW, Sandhaus RA, Strand M, Strange $C$, et al. The impact of age on outcomes in chronic obstructive pulmonary disease differs by relationship status. J Behav Med. 2014;37(4):654-663. http://doi.org/10.1007/s10865-013-9516-7

22. Schneider $\mathrm{C}$, Jick SS, Bothner $U$ and Meier CR. COPD and the risk of depression. Chest. 2010;137(2):341-347. http://doi.org/10.1378/chest.09-0614

23. Lou P, Chen P, Zhang P, Yu J, Wang Y, Chen N, et al. Effects of smoking, depression, and anxiety on mortality in COPD patients: A prospective study. Respir Care. 2014;59(1):54-61. 
http://doi.org/10.4187/respcare.02487

24. Lou P, Zhu Y, Chen P, Zhang P, Yu J, Wang Y, et al. Interaction of depressive and anxiety symptoms on the mortality of patients with COPD: A preliminary study. COPD. 2014;11(4):444-450. http://doi.org/10.3109/15412555.2013.822856

25. Goodwin RD, Lavoie KL, Lemeshow AR, Jenkins E, Brown ES and Fedoronko DA. Depression, anxiety, and COPD: The unexamined role of nicotine dependence. Nicotine Tob Res. 2012;14(2):176-183

http://doi.org/10.1093/ntr/ntr165

26. Ng TP, Niti M, Fones C, Yap KB and Tan WC. Co-morbid association of depression and COPD: A population-based study. Respir Med. 2009;103(6):895-901.

http://doi.org/10.1016/j.rmed.2008.12.010

\section{Authors Contribution:}

KB- Concept and DESIGN of the study, prepared first draft of the manuscript; GTT, BS- Interpreted the results and reviewed the literature; AJU- Statistical analysis and interpretation of results, preparation of manuscript; and $\mathrm{HN}$ - Concept, coordination, statistical analysis, preparation, and revision of manuscript.

\section{Work attributed to:}

Sri Muthukumaran Medical College and Research Institute, Chennai - 600 069, Tamil Nadu, India

\section{Orcid ID:}

Dr. Kamini B - (1) https://orcid.org/0000-0001-9162-4625

Dr. Gopinath TT - (1) https://orcid.org/0000-0003-1790-8683

Dr. Balamurugan S - (D) https://orcid.org/0000-0001-7067-7728

Dr. Arun Jayakumar U - (1) https://orcid.org/0000-0002-3536-1557

Dr. Harish Narayanan - (D https://orcid.org/0000-0001-9222-4308

Source of Funding: None, Conflicts of Interest: None. 